\title{
NOTE ON THE RATIO OF THE ELECTROMAGNETIC TO THE ELECTROSTATIC UNIT OF ELECTRICITY AS COMPARED TO THE VELOCITY OF LIGHT
}

\author{
By Harvey L. Curtis
}

\section{ABSTRACT}

The value of the ratio of the electrical units has been revised to meet the new values of the absolute determination of the ohm. This revised value is compared with the latest value of the velocity of light.

In 1907, Rosa and Dorsey, ${ }^{1}$ of the Bureau of Standards, published an article entitled "A New Determination of the Ratio of the Electromagnetic to the Electrostatic Unit of Electricity." Since that date no other determination of this ratio has been made, but there have been new determinations of the international ohm in terms of which Rosa and Dorsey expressed their result, and new determinations of the velocity of light to which they compared their result. This note is to discuss these new determinations.

In 1916 Rosa and Dorsey prepared an addendum which was to appear in later editions of their paper. However, as no such edition has been published, the addendum is given below:

\section{ADDENDUM}

In 1913 an absolute measurement of the international ohm was made by F. E. Smith at the National Physical Laboratory, London. Mr. Smith found that the international ohm is equal to $1.00052 \pm 0.00004$ absolute ohms ( $\mathrm{Phil}$. Mag., 214 A, p. 106). Consequently a value of $v$ experimentally determined in terms of the international ohm and other units will be $2.6 \pm 0.2$ parts in 10,000 less than its value in terms of the absolute ohm, all else beirig as before. It is gratifying to note that this correction is substantially equal to the unexplained discrepancy ( 3 in 10,000) between the velocity of light and the value of $v$ given in this paper. In 1907 (see above) we suggested that this discrepancy might be due to a difference between the values of the international and of the absolute ohm.

On applying this correction the value of $v$ reduced to vacuo (p. 601) and in terms of the absolute ohm becomes

$$
v_{0}=2.9979 \times 10^{10}\left[\frac{\mathrm{cm} \operatorname{Abs} \Omega}{\text { sec. }}\right]^{\frac{1}{2}}
$$

The velocity of light in vacuo (p. 603) is

$$
v=2.9986 \times 10^{10} \frac{\mathrm{cm}}{\mathrm{sec}}
$$

1 Bul. Bureau of Standards, 3, p. 433; 1907.

$$
53811^{\circ}-29-5
$$


Each of these values is subject to an estimated uncertainty ${ }^{2}$ of 1 part in 10,000; the two values, therefore, may be considered as agreeing within the limits of experimental error.

November 21, 1916.

The AUthors.

Since the above addendum was prepared, Grueneisen and Giebe ${ }^{3}$ have published another determination of the ohm which differs from that of F. E. Smith by only 1 part in 100,000, and hence would not change the above result. Unpublished results obtained at this bureau show that Smith's result is not in error by as much as 1 part in 10,000 , hence the best value to date of the ratio of the electromagnetic to the electrostatic unit of electricity is

$$
299,790 \mathrm{~km} / \mathrm{sec} \text {. }
$$

No improvement in this value can be expected until an entirely new determination is made.

The velocity of light has recently been determined by Michelson. ${ }^{4}$ The value which he obtained for the velocity in vacuum is

$$
299,796 \pm 4 \mathrm{~km} / \mathrm{sec} \text {. }
$$

A preliminary determination by Karolus and Mittelstaedt ${ }^{5}$ gave the value

$$
299,778 \pm 20 \mathrm{~km} / \mathrm{sec} \text {. }
$$

This agrees with Michelson's value within the limit of error.

The above results show that, within the limits of present measurements, the ratio of the electrical units agrees with the velocity of light. This is an important confirmation of Maxwell's electromagnetic theory of light.

Washington, March 19, 1929.

2 Note that this is estimated uncertainty and not prohahle error. The authors did not compute the prohahle error of their result, hut an inspection shows that it is considerahly less than 1 in 10,000 . No statement is made of the reasoning used in arriving at this estimated uncertainty of their result. However, for the velocity of light, the estimated uncertainty which they give agrees with the prehable error as computed by Weinherg. (H. L. C.)

${ }^{3}$ Grueneisen and Giehe, Ber. Phys. Tech. Reich., 5, p. 5; 1921. Also Ann. d. Phys., 368, p. 179; 1920.

- Michelson, Astrophys. J., 65, p. 1; 1927.

- Karolus and Mittelstaedt, Phys. Zeit., 29, p. 698; 1928. 